\title{
STUDIES OF THE VARIATIONS IN THE ANTISTREPTOLYSIN TITER OF THE BLOOD SERUM FROM PATIENTS WITH HEMORRHAGIC NEPHRITIS. I. CONTROL OBSERVATIONS ON HEALTHY INDIVIDUALS AND PATIENTS SUFFERING FROM DISEASES OTHER THAN STREPTOCOCCAL INFECTIONS
}

\author{
By WARFIELD T. LONGCOPE 1 \\ (From the Medical Clinic, the School of Medicine, Johns Hopkins University and Hospital, \\ Baltimore)
}

(Received for publication January 15, 1936)

During some studies which have been in progress for several years upon the etiology and the clinical course of acute glomerular nephritis, it was considered desirable to examine the serum from these patients for antibodies to hemolytic streptococci. Comment has frequently been made to the effect that infections by this organism involving the upper respiratory tract usually precede the onset of acute hemorrhagic nephritis, and particular attention has been drawn to this matter in previous publications (1). Efforts to demonstrate the presence of specific agglutinins and specific precipitins for hemolytic streptococci in the serum from cases of acute, subacute and chronic glomerular nephritis were met with indifferent success and very irregular results, and the investigations were being abandoned when Todd published his observations on antistreptolysin.

Todd (2) showed that the hemolysin produced by hemolytic streptococci, grown in a special medium free of animal sera, was antigenic and gave rise in rabbits to an antistreptolysin of considerable potency. Streptolysin formed by the growth of hemolytic streptococci in serum broth did not excite antibodies capable of neutralizing serum broth streptolysin nor would antistreptolysin of high titer neutralize serum broth streptolysin. Since it seemed probable that antistreptolysin might be formed in the serum of animals immunized to hemolytic streptococci, Todd tested scarlatinal antitoxin, erysipelas antitoxin and puerperal septicemia antitoxin, and found that antistreptolysin was present in high titer. Whereas the minimal neutralizing dose of normal horse serum was 0.2 cc. to $0.04 \mathrm{cc}$., the minimal neutralizing dose of the specific antitoxins was from 0.005 to 0.0002 cc. He further observed that the titers of diphtheria antitoxin, tetanus antitoxin, staphylococcus antitoxin, Small's non-hemolytic streptococcal antitoxin, antipneumococcal serum, antimeningococcal serum, and anti-gas gangrene serum did not differ from those of normal horse serum. Todd (3) then studied the reaction of the blood serum of man during infections by hemolytic streptococci. He recorded the antistreptolysin values of serum in units which are calculated as the reciprocal of the fractions of the cubic centimeters of serum employed. Under these conditions $0.01 \mathrm{cc}$. of serum equals 100 units, $0.03 \mathrm{cc}$. is equivalent

\footnotetext{
1 The titrations of antihemolysin were made with the technical assistance of Cyril Skala.
}

to 33.3 units and so forth. He found that the titers of sera from normal individuals varied between 20 units and 100 units. During convalescence from scarlet fever, erysipelas and tonsillitis, the antistreptolysin of the serum was elevated and sometimes reached 1,000 to 1,300 units. The serum from a limited number of patients suffering from infections that were not associated with hemolytic streptococcal infections gave titers of approximately normal values. During the acute phase of severe or fatal infections by hemolytic streptococcus the antihemolytic titers of the serum were not elevated. In some observations made upon the serum from nurses at the Presbyterian Hospital in New York, Todd found that during the period of normal health, or when persons were simply exposed to hemolytic streptococcal infections, that the antistreptolysin content of the serum was within normal limits. During the acute phase of streptococcic pharyngitis the titers still remained low, but during convalescence the titers rose and remained high for as long as one to three months after the infection. Todd extended his observations to rheumatic fever and found that the sera of patients in the quiescent stage gave titers that were within normal limits. During the active stage, however, the antistreptolysin content of the serum was much increased. This increase of antistreptolysin appeared to be dependent upon the preceding streptococcal infection of the respiratory tract, and did not vary with the severity of the attack of rheumatic fever. The antistreptolysin values of the serum often remained high for months during the attack of rheumatic fever and into the period of convalescence. Todd concluded that his observations afforded evidence that rheumatic fever was preceded by hemolytic streptococcal infections.

These observations on rheumatic fever were immediately confirmed and extended by Coburn and Pauli (4). They found that in the normal individual the neutralizing dose of serum was usually $0.02 \mathrm{cc}$. but might be as small as 0.01 cc. or 100 units, but rarely less. Following an attack of scarlet fever or erysipelas the titer rose from a normal figure to 0.003 or even as high as $0.0008 \mathrm{cc}$. in a case of erysipelas. In the acute rheumatic process the neutralizing dose of serum often reached $0.005 \mathrm{cc}$. or less. In inactive rheumatic fever the titers of the sera were usually within normal limits. The antistreptolysin titer of the serum remained normal during the infectious 
and quiescent period preceding the acute attack of rheumatic fever, but rose abruptly just before the appearance of rheumatic symptoms. During the first week of rheumatic fever it reached its highest level, and maintained this throughout the attack. They believed that their observations furnished strong evidence that the rheumatic attack was initiated by hemolytic streptococci. Since this first publication, Coburn and Pauli (5) have extended their studies and reference will be made to their results later on.

Since the appearance of the first papers by Todd and by Coburn and Pauli, a considerable number of articles have been published on the subject. Griffiths (6) has found high antistreptolysin in titers in all cases of acute rheumatic fever, and in a much smaller proportion of a variety of arthritic conditions. He considered 50 units as the normal. Myers and Keefer (7) give rather high figures for the normal, but since they modified the method of Todd in preparing streptolysin, and employed sheep red blood cells instead of the red blood cells from rabbits their figures can scarcely be compared with those published by others. They confirmed the preceding observations by finding high titers in proven hemolytic streptococcal infections, and comparatively high titers in acute rheumatic fever. They did not find an increase in the antistreptolysin content of the serum from patients with rheumatoid arthritis or other joint infections. They could not relate the antistreptolysin content of the serum to agglutinins for hemolytic streptococci or to the skin sensitivity to the nucleoprotein of the Streptococcus scarlatinae. The studies of Wilson, Wheeler and Leask (8) did not support the assumption that a rise in the antistreptolysin titer of the serum was conclusive evidence of streptococcal respiratory infection, and they stated that a rise in the antistreptolysin titer was not a necessary accompaniment of rheumatic fever in children.

Lippard and Johnson (9) have shown, however, that the antistreptolysin content of the serum of normal infants under 17 months of age is low, the average being 24 units and 55 per cent being 2 units or less. The average for children over 17 months of age was 66 units. In the infants there was little tendency for the antistreptolysin titer of the serum to rise following infections by hemolytic streptococci, whereas in older children the response was comparable to that observed in adults. It was further found (10) that the treatment of hemolytic streptococcal infections of infants and children by transfusions of blood or injections of streptococcal antisera was not accompanied by a significant increase in antistreptolysin substance in the blood of the recipient. Blair and Hallman (11) titrated antistreptolysin in the sera from a few normal individuals and from patients suffering from a variety of conditions. They concluded that 100 units is the upper limit of normal. The antistreptolysin titer was moderately increased in about one-third of the sera from 45 cases of rheumatoid arthritis, very high in the sera from 7 cases of streptococcal infection as well as in 15 out of 18 cases of acute rheumatic fever. They concluded that a high titer of antistreptolysin in blood serum signifies specifically infection by hemolytic streptococci.

Owing to the fact that many observers consider that the presence of distinctly abnormal amounts of antistreptolysin (over 200 units) in the blood serum is a definite indication of recent or existing infection by hemolytic streptococci, the test has been employed by some to detect such an infection. Morales-Otero and Pomales-Lebrón (12) tested the antistreptolysin titer of the sera from 41 cases of recurrent lymphangitis in Porto Rico, and since they often found the titers elevated considerably above that of their normal controls, they suggest that this condition is due to a recurring infection by hemolytic streptococci. Seegal and Lyttle (13) have determined the antistreptolysin titers of the serum from 22 cases of acute glomerular nephritis. An infection of the throat or upper respiratory tract preceded the onset of nephritis in 21 of these cases and in 15 of them the infections were associated with hemolytic streptococci. The sera were examined 6 to 57 days after the onset of the acute nephritis. Twenty of the 22 sera showed an increase of antistreptolysin titers ranging from 125 to 1250 units. They considered that their data offered strong evidence to support the contention that acute glomerular nephritis is chiefly related to a preceding hemolytic streptococcal infection.

It is unnecessary to repeat in detail the method of making the medium and preparing streptolysin. The directions given by Swift and Hodge (14), who were kind enough to acquaint us with the technique before their publications, were followed precisely. Nor is it desirable to repeat the details of performing the test, for this has been accurately described by Coburn and Pauli (5), and their method has been strictly adhered to. Todd's original "Aronson" strain of hemolytic streptococcus, which was kindly sent to us by Drs. Swift and Hodge, has been the organism used. Complete hemolysis has usually been obtained with from $0.1 \mathrm{cc}$. to $0.08 \mathrm{cc}$. of streptolysin, after it had remained sealed under vaseline at $4^{\circ} \mathrm{C}$. for 2 to 3 weeks. The hemolytic titer of each batch of hemolysin preserved in separate tubes has remained practically unchanged for months. A fresh tube of streptolysin has been used for each series of tests. Even though Hodge and Swift (15) have pointed out that the combining unit of streptolysin with serum may remain constant when the hemolytic dose varies somewhat, the hemolytic dose of each tube of streptolysin has been determined before the tests with serum were made. As a rule $2 \frac{1}{2}$ minimal hemolytic doses 
proved to be the amount which gave a constant combining power. A 5 per cent suspension of freshly drawn rabbits' red blood cells washed 6 times in 0.85 per cent $\mathrm{NaCl}$ was used for the tests. Each batch of streptolysin was titered carefully against a serum of known antistreptolysin content before it was employed for the tests. The first lots of tested serum were sent to us by Drs. Swift and Hodge. Later, Dr. Todd very kindly sent us immune serum, the titer of which was 20,000 units per cc. In each series of tests a serum of known low titer and a serum of known high titer has been used for control. For many months the serum sent by Dr. Todd was the one employed for the high titer control. The tests have been read shortly after removal from the water bath and again after standing for 18 hours at $4^{\circ} \mathrm{C}$. Except in the rarest instances the readings coincided. When they did not coincide the test was repeated.

It seemed obvious that if a study of the antistreptolysin content of the serum from patients with hemorrhagic Bright's disease was to be of any value, one should in the first place examine samples of serum from the same patient at fairly frequent intervals, and in the second place make tests on the serum from a number of normal individuals and from patients suffering from a variety of diseases in order that a fair background for comparisons might be obtained.

To this end we have examined more than 1,716 samples of sera for the antistreptolysin content from 55 supposedly normal individuals and from 516 patients suffering from a variety of conditions. The observations, for clarity of discussion, can best be divided into two parts. The first part deals with the results obtained from the titration for antistreptolysin in the serum from (a) presumably normal individuals, (b) from patients suffering from such chronic diseases as diabetes mellitus and exophthalmic goiter, (c) from patients affected by various forms of anemia, leukemia and new growths, $(d)$ from patients with chronic inactive rheumatic heart disease, (e) from patients with essential hypertension, hypertensive heart disease, chronic vascular nephritis and syphilitic aortitis, and finally from patients suffering from a variety of infectious diseases not associated with hemolytic streptococci.
In order to obtain a fair average of the natural antistreptolysin content of the serum, 84 samples from 55 supposedly normal individuals have been examined. The results are given in Table I. In each instance the highest titer is recorded. In 40 individuals, or in 74.5 per cent, the titer lay

TABLE I

Antistreptolysin titers of the blood serum from 55 normal individuals and 84 patients suffering from chronic disease

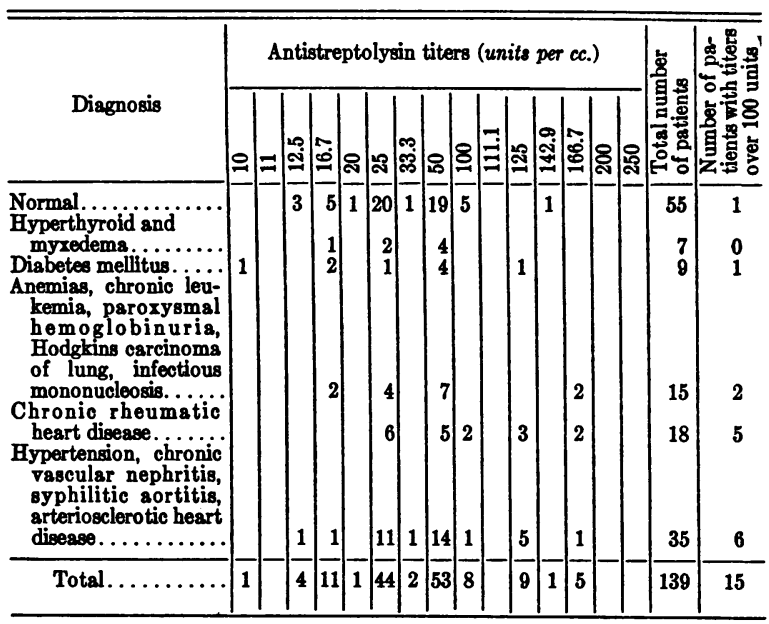

between 25 and 50 units; in 3 it was 12.5 units, and in 5 it was 100 units. In only one person was it above 100 units. In this one individual, who was apparently normal, repeated cultures from the throat failed to show either beta hemolytic streptococci or the minute hemolytic streptococci described by Long and Bliss (16); the titer on two occasions over a period of 3 months was 142.9. Eight months after the last titration, the serum showed a titer of 100 . These results are similar though perhaps somewhat more uniform than those obtained by Coburn and Pauli (5, I and VI) from a much larger series of individuals in New York. Seventy-five per cent of 146 persons showed titers of 100 or below, and the median titer for 176 persons in good health was 83 units.

Though the usual titer for antistreptolysin appeared to fall between 25 and 50 units for the adults in our series, a result that corresponds to the natural titer $(5, I)$, it seemed desirable to determine whether variations might occur in a single individual's serum over a fairly long period dur- 
ing which time he would probably contract several minor infections. The sera from five normal individuals and from one case of hypertension with chronic nephritis have been examined at intervals over periods varying from 7 months to one year. The results are given in Table II. It may be seen that the titers remain comparatively constant in spite of colds and attacks of bronchitis and, with the exception of Number 3 already referred to, they fall well within the limits of the natural antistreptolysin for the larger group.

TABLE II

Antistreptolysin titers (units per cc.) of the blood serum from 6 individuals over a period of 7 to 13 months

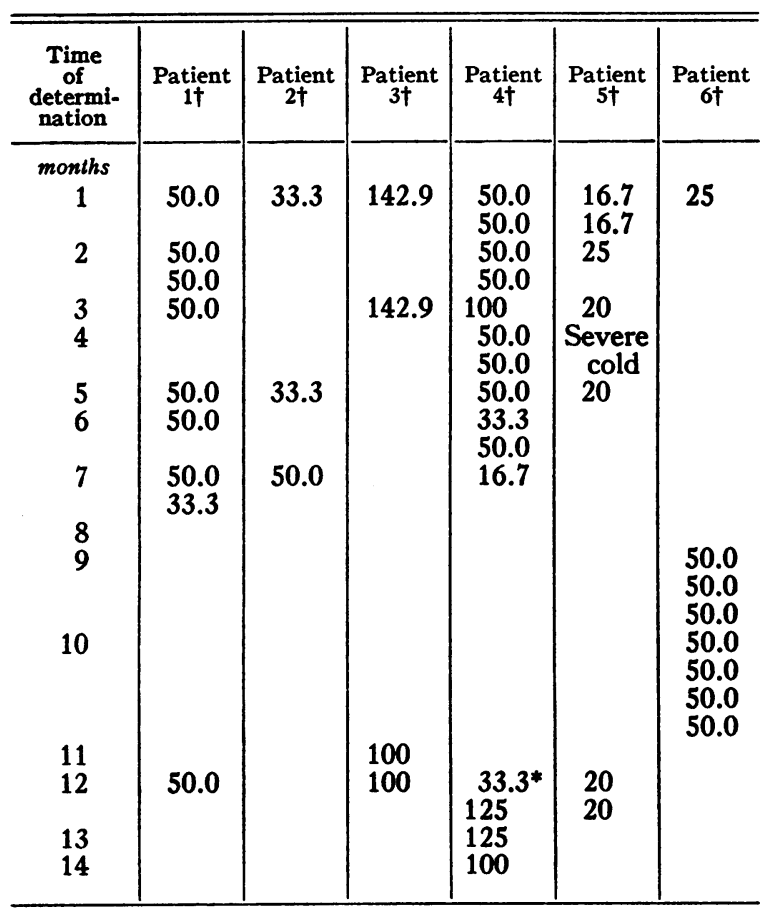

† Comments: Patient 1. Normal. Occasional colds. 2. Normal. 3. Normal. Chronic pharyngitis-repeated cultures show no B. hemolytic streptococcus or minute B. hemolytic streptococcus. 4. Normal. Several severe colds; infection of finger at * with $\mathrm{B}$. hemolytic streptococcus. 5. Normal. Repeated severe colds. 6. Hypertension with chronic vascular nephritis.

The determinations of the antistreptolysin content of sera from all the patients suffering from the various chronic diseases may be considered together. The results are compared in Table I with the normal individuals. In each instance the highest titer obtained is recorded. One hundred and fifty specimens of serum were examined from 84 patients. In several instances five or more collections of serum were made over a period of several weeks or months. The titers remained remarkably constant for each individual. In general the titers vary little from the natural antistreptolysin content of serum. In 50 patients, or a little less than 60 per cent, the titers fell between 25 and 50 units; in one case of diabetes the titer was very low for the normal adult -10 units. This corresponds to the very low titers found by Lippard and Johnson (9) in infants under 18 months of age. In 14 patients, or 16.6 per cent, the titers were slightly elevated above the natural content. There was no obvious explanation for this increase.

The infectious diseases that are included in $\mathrm{Ta}$ ble III were typhoid fever, malaria, bacterial endocarditis, meningococcal meningitis and gonococcal arthritis, a miscellaneous group including tuberculosis, epidemic jaundice, bronchitis, periarteritis nodosa and vesicular stomatitis, and finally lobar pneumonia. There were 66 individuals in this group.

\section{TABLE III}

Antistreptolysin titers of the blood sera from 66 patients suffering from various forms of acute infection

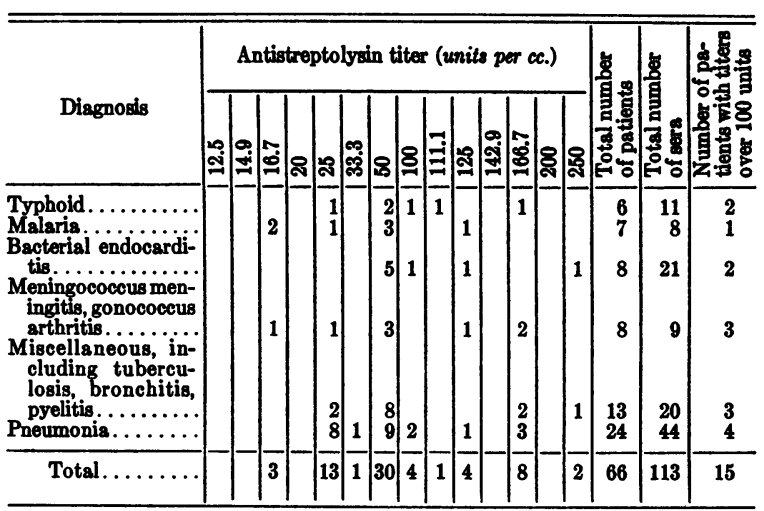

One hundred and thirteen specimens of serum were examined, and frequently several bleedings were made at intervals from the same patient. Table III gives the results of these examinations. In each instance the highest antistreptolysin titer obtained was recorded.

It will be seen that though a slightly larger 
proportion of these patients (22.7 per cent) than those suffering from chronic diseases (16.6 per cent) gave titers of antistreptolysin above the normal level, only two patients, one an instance of bacterial endocarditis and one a patient with pyelitis, showed an increase up to 250 units, a level which most observers consider to be highly significant. Since it has been remarked repeatedly that the antistreptolysin titer of the serum in infections due to hemolytic streptococci does not increase until the disease is well advanced or until convalescence has been well established $(3,4,5)$, it is important to know the day of disease on which the tests were made. The serum from three of the patients with typhoid fever was tested between the third and sixth week of the disease, and from three patients between the seventh and eleventh week of the disease. In one of these patients the serum was tested at weekly intervals for three weeks. The titer remained constantly at 50 units. In one, the serum was tested weekly for four weeks. The titer in the eighth week was 100 units; in the ninth, tenth and eleventh weeks it remained at a constant titer of 111.1 units. The sera from the cases of malaria, of meningococcal meningitis and of gonococcal arthritis were titrated only during the acute phase of the disease. The sera from the miscellaneous cases were tested at various stages of their diseases, and the sera from the cases of bacterial endocarditis weeks and months after the onset of their illness.

Especial interest attaches to the examination of the patients with lobar pneumonia, for Todd (17) has reported the fact that antistreptolysin serum of high titer will neutralize the oxygen labile hemolysin produced by pneumococci and by $B$. tetanus. The reaction was found to occur, however, only with "hyperimmune serum." This partial overlapping was not noticed when the serum from patients suffering from hemolytic streptococcal infections, which is of low titer compared with the serum from immunized animals, was studied. The serum from nine patients convalescing from lobar pneumonia due to pneumococcus Type II were tested for antistreptolysin. The serum from only one patient gave an abnormally high figure of 250 units.

The sera from 24 cases of lobar pneumonia, which are listed in Table III, were collected from the third to the fifth week of the disease. The sera from 20 patients gave titers on repeated examination that were quite constant and always within normal limits. The sera from 4 patients gave titers that were equally constant but slightly above normal. The titrations were made in the second, third and fourth week of the disease. The titers varied from 125 units to 166.7 units. The pneumonia in three of these patients was due to pneumococcus Group IV and in one to pneumococcus Type I. The blood cultures were negative in all four cases and all recovered. Of the remaining 20 cases, 5 gave positive blood cultures; two of these died, three recovered. Three patients infected with pneumococcus Type I received concentrated antipneumococcal serum and recovered. Of the 24 cases, 14 were infections due to pneumococcus Type IV; 7 were due to pneumococcus Type I; one to pneumococcus Type II ; one to pneumococcus Type III, and in one the organism was not identified.

The proportion of slightly elevated titers was, therefore, not quite as large in these patients suffering from pneumonia as it was in the meningococcal and gonocccal infections.

\section{SUM MARY}

In reviewing the results obtained from titrations for antistreptolysin in the sera from normal individuals, and from patients suffering from a variety of chronic diseases and acute infections not caused by hemolytic streptococci, it is seen that they accord in general with those previously published. It appears justifiable to conclude, as Todd did originally, that the upper limit of antistreptolysin in the serum from the normal adult is 100 units. In the majority of cases (about 75 per cent) the titer in our series lay between 25 and 50 units. The determination of the lower limit of the antistreptolysin in the normal adult is also important, for Lippard and Johnson (9) found this to be unusually low in infants under 17 months of age. In 55 per cent of these patients the titer was only 2 units. The lower level in our normal adults was 12.5 units. It is also to be observed that the titer varies very little from month to month in a given individual. The titer. appeared to be unaffected by severe colds and minor infections not due to hemolytic streptococci, 
but even a comparatively insignificant infection caused by hemolytic streptococci may result, as it did in Number 4, in a significant rise in the antistreptolysin titer within 18 days of the infection. Since such rises, as has been repeatedly shown, may persist for weeks or months, it would not be surprising to find a moderately elevated antistreptolysin titer in the serum of individuals who were apparently healthy, who showed no evidence of infection by hemolytic streptococci and who were actually unaware of having had such infections.

In view of this possibility it is noteworthy that the antistreptolysin content of the sera from patients suffering from chronic diseases and from a miscellany of infections should approach so closely the normal figure. In the examination of 155 specimens of serum from the 84 patients with chronic disease only a total of 16 samples showed titers above 100 units and none of these was above 166.7 units. The total number of patients furnishing serum showing titers above 100 units was 14 , or 16.6 per cent of the total.

Of the 155 samples of serum from the $84 \mathrm{pa-}$ tients, 139 gave titers within the average limits of normal.

In the acute infections the number of slightly elevated titers was proportionately greater, for of the 113 samples of serum from 66 patients, 22 samples from 15 patients gave antistreptolysin titers somewhat above the figure for normal adults. Titers above 100 units occurred in 22.7 per cent of the 66 patients.

It would be impossible to determine, at the present time, whether the infecting organism, such as the meningococcus or pneumococcus, was in any way related to these abnormal rises, or whether an infection by hemolytic streptococci contracted previous to, or in association with the present infection was responsible for the abnormal titer. Owing to the prevalence of hemolytic streptococci it would be impossible to exclude the latter possibility.

\section{BIBLIOGRAPHY}

1. Longcope, W. T., O'Brien, D. P., McGuire, J., Hansen, O. C., and Denny, E. R., Relationship of acute infections to glomerular nephritis. J. Clin. Invest., $1927,5,7$.

Longcope, W. T., The pathogenesis of glomerular nephritis. Bull. Johns Hopkins Hosp., 1929, 45, 335.
Lukens, F. D. W., and Longcope, W. T., Experimental acute glomerulitis. J. Exper. Med., 1931, 53, 511.

Longcope, W. T., Bordley, J., III, and Lukens, F. D. W., The Kidney in Health and Disease. Chapter XXI. Infection by Streptococci in Relation to Recovery and Progress of Nephritis. Lea and Febiger, Philadelphia, 1935.

2. Todd, E. W., Antigenic streptococcal hemolysin. J. Exper. Med., 1932, 55, 267.

3. Todd, E. W., Antihaemolysin titres in haemolytic streptococcal infections and their significance in rheumatic fever. Brit. J. Exper. Path., 1932, 13, 248.

4. Coburn, A. F., and Pauli, Ruth H., Studies on the relationship of streptococcus hemolyticus to the rheumatic process. III. Observations on the immunological responses of rheumatic subjects to hemolytic streptococcus. J. Exper. Med., 1932, 56, 651.

5. Coburn, A. F., and Pauli, Ruth H., Studies on the immune response of the rheumatic subject and its relationship to activity of the rheumatic process. I. The determination of antistreptolysin titer. J. Exper. Med., 1935, 62, 129.

II. Observations on an epidemic of influenza followed by hemolytic streptococcus infections in a rheumatic colony. Idem, p. 137.

III. Observations on the reactions of a rheumatic group to an epidemic infection with hemolytic streptococcus of a single type. Idem, p. 159.

IV. Characteristics of strains of hemolytic streptococcus, effective and non-effective in initiating rheumatic activity. J. Clin. Invest., 1935, 14, 755.

V. Active and passive immunization to hemolytic streptococcus in relation to the rheumatic process. Idem, p. 763.

VI. The significance of the rise of antistreptolysin level in the development of rheumatic activity. Idem, p. 769.

VII. Splenectomy in relation to the development of rheumatic activity. Idem, p. 783 .

6. Griffiths, G. J., Antihaemolysin titres in chronic rheumatic and allied diseases. Lancet, 1934, 2, 251.

7. Myers, W. K., and Keefer, C. S., Antistreptolysin content of the blood serum in rheumatic fever and rheumatoid arthritis. J. Clin. Invest., 1934, 13, 155.

8. Wilson, May G., Wheeler, G. W., and Leask, M. M., Antistreptolysin content of blood serum of children. Its significance in rheumatic fever. Proc. Soc. Exper. Biol. and Med., 1934, 31, 1001.

The relation of upper respiratory infections to rheumatic fever in children. II. Antihemolysin titres in respiratory infections and their significance in rheumatic fever in children. J. Clin. Invest., 1935, 14, 333. 
9. Lippard, V. W., and Johnson, P., Beta hemolytic streptococcic infection in infancy and in childhood. I. Antifibrinolysin and antistreptolysin response. Am. J. Dis. Child, 1935, 49, 1411.

10. Ibid. II. Effect of transfused blood and of streptococcic antiserum on the concentrations of antifibrinolysin and antistreptolysin in the blood of the recipients. Am. J. Dis. Child., 1935, 49, 1430.

11. Blair, J. E., and Hallman, F. A., Streptococcal agglutinins and antistreptolysins in rheumatoid (atrophic) arthritis. J. Clin. Invest., 1935, 14, 505.

12. Morales-Otero, P., and Pomales-Lebrón, A., Antistreptolysin content of sera from cases of recurrent tropical lymphangitis. Proc. Soc. Exper. Biol. and Med., 1934, 31, 1170.

13. Seegal, D., and Lyttle, John D., Antistreptolysin titre of the serum in acute glomerular nephritis. Proc. Soc. Exper. Biol. and Med., 1933, 31, 211.

Seegal, B. C., Seegal, D., Jost, E. L., and Cameron, P., Bacteriological and immunological studies of acute glomerulo-nephritis in New Orleans. Proc. Soc. Exper. Biol. and Med., 1935, 32, 1151.
14. Swift, H. F., and Hodge, B. E., A simply prepared broth for producing hemolytic streptococcal hematoxin (streptolysin), Proc. Soc. Exper. Biol. and Med., 1933, 30, 1022.

15. Hodge, B. E., and Swift, H. F., Varying hemolytic and constant combining capacity of streptolysins; influence on testing for antistreptolysins. J. Exper. Med., 1933, 58, 277.

16. Long, P. H., and Bliss, E. A., Studies upon minute hemolytic streptococci. I. The isolation and cultural characteristics of minute beta hemolytic streptococci. J. Exper. Med., 1934, 60, 619.

Long, P. H., Bliss, E. A., and Walcott, C. F., II. The distribution of minute hemolytic streptococci in normal and diseased human beings. J. Exper. Med., 1934, 60, 633.

17. Todd, E. W., A comparative serological study of streptolysins derived from human and from animal infections, with notes on pneumococcal hemolysin, tetanolysin and staphylococcus toxin. J. Path. and Bact., 1934, 39, 299. 